Trabajos y Comunicaciones, 2da. Época, № 47, e053, enero-junio 2018. ISSN 2346-8971

Universidad Nacional de La Plata.

Facultad de Humanidades y Ciencias de la Educación.

Departamento de Historia

\title{
De la locura a la normalidad. La Nación y los primeros cien días de Macri
}

\section{From madness to normal. La Nación and the first hundred days of Macri}

\section{Mauricio Schuttenberg *}

* CONICET-Universidad Nacional de La Plata

Universidad Nacional Arturo Jauretche, Argentina|mauricioschuttenberg@gmail.com

\section{PALABRAS CLAVE}

Macri

La Nación

Derecha

Discurso

KEYWORDS

Macri

La Nación

Right

Speech

\section{RESUMEN}

En este artículo se propone analizar el discurso del diario La Nación y la construcción de los primeros cien días de gobierno de Mauricio Macri. Este hecho es construido y significado como el punto de partida de una nueva era política en donde el medio condensa sus expectativas sobre el cambio y futuro del país. El artículo pretende mostrar cómo es construida la idea de normalización del país y qué implica ese proceso para este medio que expresa la visión de un periódico de derechas. 
"Al anochecer, mientras la magia de la Cenicienta se apagaba, llegó el primer signo del país del jueves. En forma espontánea, sin convocatoria ni aparato, muchos empezaron a congregarse bajo el balcón del presidente electo. No podían esperar al nuevo día para expresar su alegría. Acompañado de su mujer y su hija menor, Macri salió al balcón. No importa si esto ocurría antes o después de la medianoche. Ya era parte del jueves, día en el que amaneció otra

Argentina". 1

\section{Introducción}

Los medios construyen acontecimientos donde toman posición con el pasado y con un futuro deseado. El aspecto principal del discurso informativo es la generación de actualidad, lo que significa producción de la realidad social como experiencia colectiva (Verón, 1987). En este artículo se analiza el discurso del diario La Nación y la construcción de los primeros 100 días de gobierno de Mauricio Macri. $\stackrel{2}{=}$ Este hecho es construido y significado como el punto de partida de una nueva era política en donde el medio condensa sus expectativas sobre el cambio y futuro del país. El trabajo pretende mostrar cómo es construida la idea de normalización del país y qué implica ese proceso para el medio.

El triunfo de Cambiemos, con su lema revolución de la alegría, rompe con la histórica dificultad de la derecha argentina de lograr acceder al poder por medios electorales. Desde la recuperación de la democracia en 1983 diferentes experiencias de la derecha intentaron llegar al gobierno y ninguna tuvo éxito como partido "puro". Interesa entonces analizar las posturas, las demandas y la construcción del contexto histórico de llegada del nuevo gobierno de derecha y sus posibilidades de acuerdo con este matutino.

Se abordará el discurso de La Nación puesto que conforma una agenda y una línea editorial en busca de articular un colectivo de identificación, en tanto entidad marcada por la utilización del nosotros en el plano enunciativo que permite reforzar la relación entre el enunciador y el prodestinatario (Verón, 1987). En palabras de Tocqueville

“...en los países democráticos sucede muchas veces que un gran número de hombres que tienen el deseo o la necesidad de asociarse, no pueden hacerlo, porque siendo todos muy pequeños y estando perdidos entre la multitud, no se ven ni saben en dónde encontrarse. Aparece un periódico, que expone a los ojos del público el sentimiento o la idea que se presentó simultáneamente y en forma separada a cada uno de ellos; entonces todos se dirigen hacia esta luz, y aquellos espíritus vacilantes que se buscaban hacía largo tiempo en las tinieblas, se encuentran al fin y se reúnen" (1957: 402).

Para esto, partimos de concebir al diario La Nación como un actor que interviene desde su propio núcleo de intereses, además de constituir un soporte y espacio difusión de las ideas políticas de los sectores conservadoresde nuestro país. . $^{3}$ A lo largo de la historia Argentina, los periódicos han sido actores fundamentales para la divulgación masiva de las ideas y de los intereses políticos, económicos, sociales y culturales de diferentes sectores sociales. Jugando un rol político, en tanto articuladores de una perspectiva que partiendo de una representación de la sociedad y sus conflictos, presuponen una serie de acciones y medidas de gobierno con las cuales dar una respuesta programática.

El trabajo apunta además a construir un conocimiento sobre los discursos de "derecha" en la Argentina contemporánea e indagar cómo se resignifica el pasado en los posicionamientos del presente y la forma en que se construyen los relatos a partir de la reivindicación de distintos procesos históricos, tradiciones y figuras. 
Profundizar en las dinámicas políticas de estos espacios es fundamental a la hora de pensar el proceso en su conjunto. Como señala McGee Deutsch (2005) los investigadores se sienten más atraídos por las revoluciones que por los grupos que se oponen a ellas. Estas ideas y posicionamientos no han sido lo suficientemente indagados y resulta indispensable producir un conocimiento en esa área para dar cuenta del proceso abierto en 2015. El artículo analiza el discurso de unos de los tradicionales diarios liberal conservadores y su articulación discursiva en busca de legitimidad hegemónica.

\section{II.}

La metodología empleada se inscribe en lo que Vasilachis (2009) denomina como paradigma interpretativo, que deposita la mirada en los procesos de producción de sentido. En esta línea, se toman aportes de diversos campos disciplinares como el análisis del discurso, la teoría política y la comunicación social.

El artículo se basa en un análisis político del discurso desde una mirada teórica metodológica posfundacional. Esta perspectiva se construyó a partir de diversos autores y algunas categorías centrales de esta línea analítica. Conceptos como identidad, hegemonía, relato, significantes vacíos, fronteras identitarias, cadenas de equivalencias y articulación política fueron los que resultaron particularmente sensibles para abordar las fuentes y dar cuenta de los objetivos del trabajo.

Analizar discursos implica pensar las formas en las cuales las identidades buscan construir consensos en torno a sus ideales, esto es, la disputa por la hegemonía que supone la significación de la totalidad. Una totalidad que aspira a partir de un particular que, sin dejar de serlo, comienza a vaciarse de contenido, inscribiendo otras particularidades (Laclau, 2005). ${ }^{4}$ Estas particularidades se construyen como cadenas de equivalencias que articulan distintas particularidades. En este sentido, interesa pensar cómo se intenta consolidar una nueva formación ideológica y disputar la hegemonía (Schuttenberg, 2014). Por ello el discurso del medio construye una mirada del mundo desde el prisma conservador, lo que hace necesario investigar en profundidad la conformación de ese relato. $\underline{5}$

Las identidades se constituyen en la conformación de un relato que busca su trascendencia en un pasado y un futuro acorde a sus concepciones. Coincidimos con Barthes (1999) en señalar que el relato está presente en todos los tiempos, en todas las sociedades y en todas las ideologías. No es posible construir una identidad sin relatos que le den sentido. Esto apunta justamente a uno de los objetivos centrales de nuestro aporte: tratar de analizar el discurso del medio en tanto relato que busca la conformación de su pasado y futuro. Para ello es central la noción de identidad puesto que a partir de allí se recortan dos dimensiones significativas: la representación de la sociedad y el programa político (Eccleshall, 1993). Según Eccleshall (1993), las identidades ofrecen una visión de la sociedad inteligible y para ello acentúan y contrastan distintos aspectos del mundo social a fin de ilustrar cómo actúa la realidad en todo su conjunto y también cómo se debería organizar desde el enfoque propuesto. A partir de este desarrollo se transmite un programa de acción en busca de acercar el ideal (Schuttenberg, 2014).

A la hora de operacionalizar este concepto, es necesario pensar que toda identidad política se constituye en referencia a una interpretación del pasado y una construcción del futuro deseado que se conjugan para dotar de sentido a la acción presente. Por ello, para un análisis de las identidades políticas, la identidad referenciada en la historia y en la política quedan de manifiesto en el hecho que el pasado-siempre abierto- puede ser reconstruido en función de un presente y un porvenir (Baczko, 1991).

La construcción de una memoria resulta de la transmisión de ciertos acontecimientos y experiencias que una identidad posee interés en conservar, de allí que la memoria más que un conjunto homogéneo y coherente de representaciones del pasado tiene que ser pensada como el lugar de una tensión entre el pasado que ella custodia y los conflictos que la conforman y la reformulan (Jelin, 2001 y 2002). En este sentido, el concepto de memoria discursiva (Courtine, 1981) remite al interdiscurso, al cuerpo socio-histórico de trazos discursivos previos en los que una secuencia se inscribe, en la medida en que esta secuencia pone necesariamente en juego un discurso-otro, 
una red de tópicos y filiaciones históricas.

Analizar discursos no consiste en estudiar lo que los actores dicen por oposición a lo que hacen. Como sostienen Verón y Sigal (2004), el análisis de los discursos es indispensable para identificar los mecanismos significantes que estructuran el comportamiento social, sin hacerlo no comprenderemos tampoco lo que los actores hacen. De esta manera, los discursos interesan analíticamente en tanto es imposible interpretar la acción política fuera de toda hipótesis sobre la matriz significante que la genera.

Para la selección del material se tomaron en cuenta los editoriales, notas de opinión de periodistas y columnistas del medio publicados en los primeros 100 días de gobierno. $\underline{6}$ Este recorte se justifica en el interés de los medios por hacer una "primera evaluación" de Cambiemos en el poder. ${ }^{7}$ El artículo apunta a pensar a partir de un análisis del discurso en su dimensión argumentativa cómo se construye desde el medio la "normalización" del país, qué lugar tendrán el Estado y la política.

\title{
III.
}

El análisis de los 100 primeros días de los gobiernos tiene una tradición en la prensa argentina puesto que marcan la llegada de un proyecto político al Estado y representan un desafío fundamental que define la posibilidad de desarrollar las propuestas y concepciones ideológicas y programáticas. Es en ese momento, los actos de gobierno son conducidos por un preciso plan de acción que busca producir efectos políticos concretos. Se pretende mostrar cómo es construida la idea de normalización del país y qué implica ese proceso para el medio. En ese plano se desarrollarán las argumentaciones ordenadas en torno a ejes que se construyeron a partir del análisis de las fuentes.

\section{III. a. La pesada herencia ¿Qué es/fue el kirchnerismo?}

Desde el 10 de diciembre de 2015 el diario publicó una serie de editoriales y notas de opinión en donde el tema a desentrañar era la naturaleza del gobierno que acababa de dejar el poder. El medio dedicó numerosas páginas a describir la gestión previa a Macri, a explicar los fundamentos de su poder y los supuestos engaños a los que habría sometido a la sociedad.

Las páginas del diario se centraron en destacar la interpretación del kirchnerismo como los años de despilfarro, mala administración, mafias, etc. Las dos presidencias de Cristina Fernández se caracterizaron como corruptas en esencia. La corrupción no era de algunas situaciones o personajes del gobierno, sino que esta iba más allá, era constitutiva del kirchnerismo como movimiento político.

\begin{abstract}
"Es posible que allí radique la esperanza compartida por quienes votaron al nuevo gobierno en la primera vuelta y quienes lo hicieron en el ballottage: el piso mínimo de expectativas de quienes están convencidos de la necesidad de bloquear la continuidad del kirchnerismo no sólo para terminar con la destrucción del espacio público y los bienes comunes, tanto materiales como simbólicos, en la que aquél parecía empeñado, sino también para poner un freno al desarrollo de los mercados clandestinos cada vez más extendidos al amparo de los vínculos crecientemente estrechos entre política, fuerzas de seguridad y crimen organizado". .8
\end{abstract}

El triunfo de Mauricio Macri expresaba, según esta perspectiva, la necesidad de nuestro país por volver a resignificar determinadas palabras y acciones. Después de doce años de un poder político "arrogante, pendenciero, avasallante, irrespetuoso para con los críticos y, muy especialmente, vengativo, apelar a la reconciliación, al diálogo y a la unión para alcanzar objetivos termina siendo necesariamente una de las principales demandas que se le hace a nuestra maltratada democracia". .9

El kirchnerismo fue conceptualizado como una falta de republicanismo en la práctica política. A lo largo del 
período, según la visión del medio, la política de derechos humanos, la redistribución del ingreso y la integración de sectores excluidos de la vida socioeconómica, las nacionalizaciones y estatizaciones y, en suma, el resto de las políticas de Estado cumplieron la función de ser auxiliares de una retórica articulada para convencer y sumar voluntades sociales colectivas de la esfera pública, a un proyecto individual, con origen y destino en la esfera particular. En este marco, la construcción discursiva del kirchnerismo como antirrepublicanismo autoritario, como un poder emancipado y no representativo de la voluntad popular fue constituyéndose como articulador de la argumentación.

En ese marco, la idea de un gobierno autoritario fue estructurando la significación que construyeron sobre el kirchnerismo. Anudado a ello, la cuestión de una política de confrontación entre argentinos era el eje central de un populismo que había intentado ir por todo.

\begin{abstract}
"En esa concepción, el que piensa distinto no es visto como un diferente que aporta sino como un enemigo que amenaza. No se lo considera porque no se lo valora. Hay monólogo, no diálogo; poder, no mediación; mayoría, no consenso. Ese pensamiento único militariza la política: el líder es el jefe; el militante, un soldado; el que cambia, un traidor; los objetivos son batallas; la meta es la victoria. La idea bélica de la política reduce las instituciones republicanas y la división de poderes a formalidades del institucionalismo y las subordina al triunfo de la propia causa". $\underline{10}$
\end{abstract}

El populismo y su crítica se construyen en el discurso también en articulación a una corrupción que le sería constitutiva. A su vez, ese régimen sería lo opuesto al Estado de Derecho que es su reverso positivo. El relato en torno al poder es central y en esa cadena de significación el poder es concebido como un objeto con valor en sí mismo, es decir los gobernantes desearían el poder por el poder mismo. Esta forma de pensar el poder implica un despolitización de la acción política puesto que en esa práctica no habría lugar para las utopías, los proyectos de país, etc., sino sólo una acumulación del mismo. Partiendo de esta idea, las políticas desplegadas por el kirchnerismo no expresarían una convicción profunda de cambio social, sino que habían tenido una intención manipuladora y pragmática en la búsqueda de acrecentar su poder personal (Schuttenberg y Fontana, 2013). Esta visión del poder y la política se articulan en una tradición liberal sobre el rol del Estado

"El gobierno saliente hizo un culto de la distorsión de la verdad. Tuvo logros y errores, como tienen otros gobiernos. Pero degradó el "relato", la narración de una historia real o ficticia, al "cuento del tío", que es una forma de mentira sistemática. Alguien deberá estudiar las cortinas de humo generadas cada semana para marcar la agenda y distraer la atención. El relato fue la forma de comunicar una idea, o mejor, una ideología, en el sentido negativo del término: una mirada parcial que niega u oculta facetas de la realidad". $\underline{11}$

La caracterización del kirchnerismo en los anteriores términos les permite empezar a delinear tras ello el modelo económico que toman como el correcto. Así, la eliminación de las retenciones a las exportaciones, el poner fin a lo que denominan el cepo cambiario y liberar las operaciones de compraventa de moneda extranjera, contribuía a frenar la fuga de capitales, y permitir la llegada de inversiones.

La acción reguladora del Estado es identificada naturalmente como corrupta o tendiente a ello, por esa razón debe limitarse a ciertas cuestiones. Allí, plantean con precisión los lineamientos económicos que el Estado debería seguir y vuelve a instalar la idea de un Estado que asfixia la actividad privada, por lo que el plan de acción debería consistir en liberar las fuerzas del mercado para que desarrollen el país. Además, el Estado populista, en esta lectura, trae consigo una tendencia al autoritarismo y a la corrupción. El significante corrupción se coloca en el punto nodal del discurso de los diversos sectores de la oposición y estructura una interpretación antipolítica de la política.

"Hará falta mucho esfuerzo y delicadeza para desactivar la bomba de tiempo que deja el kirchnerismo en lo económico y social. También el desquicio que deja en lo cultural, en los modos 
y en las formas. Conseguir poner al país en la senda de la normalidad perdida es una meta razonable, aunque ciertamente difícil". $\underline{12}$

Según Hobsbawm (1994), la característica de las derechas es concebir la desigualdad como un dato "natural", consustancial al orden humano. En ese marco, para los sectores conservadores, toda tentativa de modificación social impulsada por grupos subalternos es considerada como un cuestionamiento del orden natural.

Uno de los ejes discursivos primordiales del medio es el retorno a la normalidad. ¿Qué significación adquiere esto? La normalidad es de alguna forma cerrar el ciclo kirchnerista. Es decir, las políticas redistributivas del kirchnerismo y la politización de la sociedad son la frontera antagónica de la identidad política del medio. La vuelta a la normalidad es volver atrás los avances producidos a partir de 2003, es un giro conservador de larga tradición.

En la búsqueda de ese orden hay una articulación con un pasado presente en el recuerdo de la Argentina de principios de siglo XX donde la tradición liberal era hegemónica. Esta mirada se articula en el discurso con otro eje que identifica al kirchnerismo como el productor de una división binaria falsa del espacio político en la que el gobierno representaba los intereses del pueblo, y sus adversarios eran presentados como portavoces de intereses de las grandes corporaciones.

El origen de la desviación en el discurso se establece en 1930, es decir en el momento en el cual comienza a discutirse el modelo agroexportador. Según el medio esto no obedece sólo a cuestiones de política económica, sino más bien a una decadencia moral de nuestra sociedad.

"La decadencia de la Argentina lleva más de 85 años, desde que se inició con el golpe de estado de 1930, aunque se pueden detectar síntomas anteriores a esa fecha. Nuestro problema es un problema moral dado que nuestra moral es muy acomodaticia, una moral de conveniencias, sin principios ni convicciones firmes. El sindicalismo, creado y manejado desde arriba por los gobiernos, la columna vertebral de un movimiento político, logra por distintos mecanismos de recaudación compulsiva a la población financiamiento para sus tareas sindicales aunque también para ellos mismos, individualmente". $\underline{13}$

Identificar un pasado ideal en la etapa agroexportadora los posiciona fuertemente en el debate político económico de los últimos años. En este aspecto, la promoción de políticas de industrialización son interpretadas como intromisiones al mercado y como el abandono de un destino histórico. Esa lectura se articula discursivamente con la idea moral, es decir, el abandono de nuestro rol primario implica la aparición de nuevos sujetos que rompen esa normalidad pretendida. Así el sindicalismo atenta contra los esforzados productores.
"Las políticas industriales deben revisarse a la luz de las experiencias globales. En tiempos de flujos dinámicos, el proteccionismo debe utilizarse para facilitar las transformaciones con inclusión y no para conservar estructuras productivas poco competitivas que afectan a los consumidores. Las políticas deben ser acompañadas por una inteligente apertura de mercados en el marco de la reorganización mundial del comercio". 14

Dar marcha atrás con el modelo económico abierto en 2003 es central en la argumentación puesto que "desde Diocleciano hasta la fecha han fracasado rotundamente todos los intentos de establecer "precios cuidados" (un eufemismo para precios máximos). El pretendido control de precios, aunque sea circunstancial, siempre produce cuatro efectos central que no sólo postergan la recuperación sino que agravan la situación". 15 Es decir, la acción del Estado para regular los mercados siempre es nociva para el desarrollo económico y la prueba es la historia.

La regulación del Estado es articulada en una cadena de equivalencia con el corporativismo y el fascismo. De esta forma, los acuerdos de precios y salarios propios de las políticas aplicadas por el kirchnerismo, en realidad son interpretadas en un ciclo histórico más amplio que viene desde los años treinta. Según esta lectura presente en 
numerosos artículos y editoriales, el tamaño de la gigantesca estructura gubernamental que carcome la productividad de todos.

\begin{abstract}
"En El espíritu de la Revolución Fascista, donde se recopilan los discursos de Mussolini, después de hacer una apología del corporativismo concretado en acuerdos de precios y salarios, el "Duce" sostiene que esa es la manera en que "hemos sepultado al Estado democrático [.]. A ese viejo Estado que enterramos con funerales de tercera, lo hemos sustituido por el Estado corporativo". Esos acuerdos "entre el capital y el trabajo" son reiterados en el manifiesto fascista de Verona y copiados por los populismos de toda laya con los resultados conocidos". $\underline{16}$
\end{abstract}

Democracia es libertad de mercado y regulación económica es sinónimo de fascismo. La historia sirve para "aprender y no tropezar con la misma piedra, dados los repetidos antecedentes en materia de control de precios y absurdos acuerdos de precios y salarios, como si un grupo de capitostes reunidos en un cuarto, concentrando ignorancia, pudiera sustituir los millones de arreglos contractuales en un contexto de conocimiento disperso y fraccionado" 17 . La frontera discursiva se construye articulando esa otredad contra la libertad de los miles de emprendedores que sin trabas "ficticias" conforman el mercado.

En lugar de esa libertad, el diario trazaba un diagnóstico de la situación y señalaba que nunca antes el empleo público había tenido un crecimiento tan "descontrolado y de consecuencias tan gravosas para la economía del país como durante los últimos 12 años". En el mismo sentido, denunciaron que "se han alimentado y mantenido plantas estatales de dimensiones elefantiásicas, llegando al ridículo de no poder explicar siquiera su relación proporcional respecto del total de la población en muchos puntos de nuestro territorio". $\underline{18}$ El sobre dimensionamiento del Estado es producto de las políticas tomadas y esto constituía el gran problema a abordar. La tarea del nuevo gobierno era contar con un Estado eficiente y para ello habría que imprimir un nuevo aire a la gestión.

\title{
III. b. Los desafíos
}

Las ideologías políticas comparten dos características principales: una representación de la sociedad y un programa político (Eccleshall, 1984). En este aspecto, el discurso buscará vincular estos dos niveles, es decir acercarse al fin deseado a través de una perspectiva coherente.

En el apartado anterior se desarrolló el diagnóstico de la situación del país que el medio construyó. Sin embargo, al mismo tiempo, el matutino fue describiendo uno a uno los distintos desafíos que se asomaban en el corto y mediano plazo. Como se señaló el 2015 lo caracterizan como una crisis no limitada al plano económico, sino que se extiende a todos los órdenes de la sociedad. La democracia se hallaba en peligro por el crecimiento de la inseguridad, del narcotráfico, una degradación de la educación y el surgimiento de una cultura corrupta como un flagelo contra el ciudadano honesto. En definitiva, la sociedad se encontraba en situación crítica a partir de un gobierno que había atropellado las instituciones de la República.

Semejante diagnóstico se insertaba en el debate que se estaba dando en los medios y dentro del seno del nuevo gobierno. Este tenía como eje el carácter del remedio a emplear para reencauzar y normalizar el país. Así, algunos se mostraban a favor de una opción denominada gradualista que consistía en de a poco ir retrocediendo el lugar del Estado conquistado durante el kirchnerismo, mientras que otros se volcaban a una opción más dura: impulsar rápidamente los cambios socio económicos para restablecer el orden liberal. Dentro de ese debate, La Nación optó por apoyar la salida "dura” puesto que el gradualismo hacía imposible salir de la decadencia.

“Ante este panorama, no se reencauzará al país en la senda del progreso y la equidad con una combinación de pragmatismo y gradualismo. Lo que se necesita es un New Deal argentino. Que enfrente con decisión las recetas gatopardistas que nos han traído hasta la decadencia actual. Y es que al igual que en el antecedente de Roosevelt, la suerte del gobierno del presidente Macri en buena parte se jugará en sus primeros cien días de gobierno. ¿Cuáles deberían ser las líneas 
maestras de un New Deal argentino?".19

Ese gran acuerdo, distaba de ser una receta gradualista, sino más bien lo contrario. Es interesante la argumentación en torno a evitar el gatopardismo de una política de cambios gradual. El gatopardismo fue utilizado como crítica "por izquierda" a los gobiernos nacional populares ante lo que, algunos sectores de la izquierda, entendían como falta de profundización o avance del proceso redistributivo. La apelación al New Deal se construye como momento de quiebre y de surgimiento de un modelo societal completamente distinto al anterior. Así esta nueva política debía recuperar las instituciones republicanas y reinsertar a la Argentina en el mundo, combatir contra el narcotráfico y lograr la unión de los argentinos.

"Un New Deal argentino se podría basar en "cinco letras i" que sean la prioridad para los próximos años: Instituciones, Indigencia, Inversiones, Inseguridad, Inserción internacional. Es decir, prioridades para la política, la solidaridad social, la economía, la vida de las personas y las relaciones exteriores". $\underline{20}$

Emprender un giro tan sustancial de la política no era una tarea sencilla para el nuevo gobierno. La misión era resolver una crisis anterior del 2001 aún no superada. El 2001 se constituye como mito fundante de lo que identifican un debería construir un nuevo acercamiento a la política. En ese relato histórico, la crisis de 2001 es un parteaguas, aunque diferente de los relatos nacional populares que interpretaban dicha crisis como el fin del proyecto neoliberal. Las identidades conservadoras articulan un discurso en el cual la significación de 2001 está vinculada más al fracaso de una forma "antigua" de concebir la política, que se plasma en la demostración del fracaso de las ideologías del siglo XX.

Una gestión que se enfrenta al desafío de poder borrar la "vetusta política argentina, sus viejos códigos y sus anquilosadas estructuras". Se debía dejar atrás a la dirigencia política que debió irse con la gran crisis de 2001 y que, por el contrario, encontró un refugio oportuno en el kirchnerismo. Allí construyen al Pro y la alianza Cambiemos como una nueva referencia que nada tiene que ver con la política argentina de los últimos años.

En ese marco, la tarea es compleja puesto que "Cristina Kirchner no le dejó nada a Macri; sólo deudas, escasez y conflictos". Allí apelan a la historia para marcar un temor que sólo la denuncia del Estado real de las cuentas podría, según esta visión, evitar. La memoria que construyen es que y De la Rúa recibieron un desastre y los dos terminaron mal por no ser claros con la herencia recibida. El temor es que "Macri no tiene derecho a terminar mal sin que el país corra el riesgo de volver a la receta autoritaria del populismo". $\underline{21}$

Otro de los desafíos que aparecen en la visión del medio es la necesidad de unir a los argentinos. La grieta atribuida al kirchnerismo hacía necesario superarla por el bien de la comunidad. Este también es un aspecto central en lo que podríamos denominar el proceso de normalización del país.

Este relato construye una interpretación de lo social desde el individualismo más extremo. Lo colectivo no existe, solo el sujeto individual. Únicamente el individuo es el protagonista de la historia y el Estado debe limitarse a proteger los derechos de los individuos (Casullo, 2007). Como bien señala este autor, la comunidad se reduce al individuo y la visión sobre las derechas es fundamental para empezar a delinear el análisis. La lectura es que la política, a diferencia de la etapa kirchnerista, no debería considerarse conflictiva sino más bien como consenso sin conflicto (Conno, 2012). En este discurso, la política tiene que ver con el consenso como punto de partida, no como resultado de la lucha política. Pensar en estos términos implica una negación de la política y su reemplazo por una visión que vela los conflictos y la disputa de intereses.

La conformación de un relato kirchnerista durante los años anteriores es vinculado a una visión sesgada que tiende a fracturar a las sociedades. Como reverso a esa lectura, está la búsqueda de valores y objetivos nacionales que contengan a la sociedad en su conjunto. Alemán (2016) da cuenta de esta operación discursiva caracterizada por la negación de lo político como instancia conflictiva, más allá de que en su enunciación la figura del populismo confrontativo es espectral, es decir está fuertemente presente, pero como telón de fondo no explicitado. El 
discurso de La Nación propone negar el conflicto y "cerrar la grieta" que los gobiernos kirchneristas habrían abierto. Así el relato $k$ está identificado con una mística falsa que sirve a los intereses de construir una verdad sesgada producto de un exceso de politización toda interpretación alternativa de los hechos. Esa confrontación, según el medio, es promovida por el kirchnerismo y los adeptos del nuevo gobierno quedarían excluidos o impedidos de mostrar sus simpatías. Para ilustrar esta maniobra "clásica del populismo autoritario que plantea la necesidad de quebrar decididamente a la sociedad con una dicotomía de hierro: patria y antipatria", desarrolla una escena del enfrentamiento.

\begin{abstract}
"Un simpatizante kirchnerista entra en el vagón del subte y va repartiendo un panfleto: parece que Macri es una mezcla de Videla y Martínez de Hoz. Todos los pasajeros aceptan el libelo por cortesía o por curiosidad. Uno, sin embargo, lo rechaza. Entonces el repartidor lo hostiga, desafiante, y el aludido responde con dureza. No es un debate ideológico, sino un electrizante cruce de acusaciones e insultos. Una cosa lleva a la otra, y de pronto el vagón es un ringside: los púgiles se lastiman en medio de un tornado de ademanes y griterío". $\underline{22}$
\end{abstract}

En la anterior escena, se reedita una suerte de civilización versus barbarie, en donde los ciudadanos no pueden mostrar sus simpatías ante el ataque de seres irracionales que actúan como fanáticos kirchneristas. El conflicto es impulsado por una fuerza ciega y autoritaria que sigue los designios del anterior gobierno. Además, la anécdota apela a la vivencia y le busca darle cuerpo a la violencia que se estaría desatada. El problema es presentado como complejo puesto que la herencia es económica, cultural y social. La solución que se impulsa desde el medio debe ser rápida y eficaz. Porque "lo que no se lleve a cabo en los primeros meses, será más difícil de encarar más adelante". $\underline{23}$

El tiempo y la forma de encarar el enorme desafío que presenta la normalización del país son fundamentales para el medio ya que dedicó varios editoriales y notas de opinión al tema. El problema que plantean es que la ciudadanía puede perder rápidamente la confianza en el gobierno a partir de un ajuste que consideran necesario ante la herencia de un "Estado fundido".

"El reto político del momento se parece un poco a la famosa Cámara de Tortura China: Houdini era esposado boca abajo e introducido en una caja llena de agua con el mandato de escapar o morir en menos de tres minutos. El resultado electoral podría traducirse como una analogía de aquella desesperación: la sociedad le encomendó a Cambiemos desactivar varias bombas de relojería, pero al mismo tiempo lo ató de pies y manos. Y corre el riesgo de ahogarse si no entiende su papel histórico: ser el Presidente de una transición entre un régimen rancio de partido único y un país normal con acuerdos democráticos que tendrá en el futuro nuevos jugadores a izquierdas y derechas. $\underline{24}$

Esta preocupación fue retomada durante las primeras semanas. El gran problema era "el déficit fiscal más alto del último medio siglo, agravado por una presión impositiva impagable que financia un gasto público homérico, producto esencialmente de un empleo público de más de 4.000.000 de personas (casi 30\% del total del empleo en el país) con una bajísima productividad". $\underline{25}$

"A la sociedad le cuesta entender que un empleado público "ñoqui" o que no tiene nada que hacer no sólo es una estafa al contribuyente, sino que es de una ineficiencia extrema porque se le está quitando al sector privado un ingreso que podría asignar con mucho más criterio y eficiencia que el Estado, generando más trabajo y empleo productivo. Es falso que un empleado público menos sea un desempleado más. No hay ningún motivo para pensar que el sector privado no lo contrataría". $\underline{26}$

Este aspecto es constitutivo de la argumentación puesto que la ciudadanía debería comprender la necesidad de 
moderar el crecimiento y el consumo. Así el discurso reconoce las políticas aplicadas por el kirchnerismo que "no sólo le devolvió a la sociedad el nivel de consumo previo a la crisis de 2001, en el ciclo consumista más extenso de nuestra era, sino que repartió en consumo toda la plusvalía de los precios excepcionales de las materias primas" pero realiza una valoración negativa de ello. Justamente, ese proceso se dio de la mano de "la construcción de ese relato perverso y distorsivo donde el salario de los argentinos es algo sacrosanto que no se puede negociar". $\underline{27}$

El gran interrogante que intentan responder es el de cómo desarmar las políticas del ciclo kirchnerista sin generar un costo social en amplios sectores de trabajadores. El planteo se basa en abandonar el modelo consumista irreal de la etapa anterior y reemplazarlo por el modelo de ahorro e inversión que impulsaría el nuevo gobierno. Para sostener la idea retoman algunas comparaciones con otros países. De este modo, desarrollan una interpretación de Japón como un país que casi sin recursos se convirtió en pocas décadas en uno de los más desarrollados, y el de la Argentina, país que a principios del siglo XX caminaba raudo hacia el desarrollo con la educación como emblema y todos los recursos a su disposición y que, sin embargo, retrocedió y quedó en el subdesarrollo. La explicación es histórica puesto que, según el medio, Argentina hace setenta años comenzó a gastar más de lo que producía.

"Por eso, es fundamental que la sociedad comprenda y sea tolerante con el esfuerzo que se está iniciando y sepa que la gran inversión -sobre todo la inversión directa- puede tardar en llegar, que no es cosa de un día para el otro. Hay un camino arduo por delante que exige mucha disciplina. Muchas de estas medidas van a repercutir de algún modo en el consumo general de la sociedad. Si ningún sector está dispuesto a sacrificar un palmo de su parcela de consumo, aunque más no sea transitoriamente, poco de esto se podrá implementar."르

La argumentación se cierra apelando a la necesidad de un esfuerzo compartido del conjunto de la sociedad para atraer inversiones. Allí vuelven a tomar las recetas de ajuste del gasto estatal como paso necesario para la puesta en funcionamiento del nuevo modelo a partir del derrame que ocasionaría el crecimiento de la actividad.

\section{III. c. Reescribir la historia reciente}

En sintonía con la mirada sobre la naturaleza del proceso post 2001 y en vinculación con los desafíos del postkirchnerismo se articula una visión de discutir la idea del "relato". Este es un de los ejes transversales del medio puesto que desde tiempo atrás a 2015 ya venían publicando editoriales y notas de opinión que discutían ciertos consensos en torno a los hechos de la historia reciente, fundamentalmente la última dictadura (Schuttenberg y Fontana, 2016).

Hay una intensión de revisar el consenso kirchnerista en torno a la interpretación de estas etapas históricas. El triunfo de Cambiemos repuso en los primeros planos otras interpretaciones sobre la historia que se tomaron con puntos nodales de la construcción de un discurso sobre nuestro pasado contemporáneo. En ese contexto reabren el debate sobre los años 70 , el rol de la dictadura y las organizaciones políticas. Allí la revisión del pasado se imprime sobre la antigua interpretación de los dos demonios y sobre la idea de que es hora de construir una memoria completa.

\footnotetext{
"En una sociedad democrática, el Estado debe satisfacer la justa necesidad del pueblo de conocer con veracidad los hechos dolorosos de su pasado. Y esta necesidad se acrecienta cuando se advierte la prácticamente nula actividad del Estado y de no pocas entidades de derechos humanos por conocer la magnitud de la acción terrorista cometida por organizaciones como Montoneros y el ERP contra la población civil y no combatiente". $\underline{29}$
}

Asimismo, otros elementos simbólicos comenzaron a cuestionarse en las páginas del diario. En este aspecto, las notas apuntan a discutir el ideario latinoamericanista que impulsaba la gestión kirchnerista. El eje central de la discusión se basa en la desmitificación de la historia y del relato $\mathrm{k}$. 
"Los Kirchner bajaron algunos cuadros, pero subieron otros. En tal subibaja de la política le ha tocado días atrás a uno de ellos, al que gobernó entre 2003 y 2007, y al déspota venezolano Hugo Chávez ser removidos de la Galería de los Patriotas, habilitada años atrás con criterio sectario en instalaciones de la Casa Rosada. Está bien lo que ha ocurrido ahora. Más dudas presenta, al menos en el caso del verborrágico autócrata bolivariano, la determinación de enviarlos al Museo del Bicentenario. Nada justifica entreverar a estas alturas a Chávez con la evocación de los momentos de grandeza excepcional de la argentinidad". $\underline{30}$

Así cuestionaban la figura de Hugo Chávez por ser un político autoritario y ponerlo en el pedestal de la galería de los patriotas era reivindicar la posibilidad de tomar sendas no democráticas. En el mismo sentido, se impugnaba la figura del Che Guevara quien si bien "hay quienes consideran que encarna sueños de rebeldía, pero nada de eso alcanza para que se halle al lado de José de San Martín o de Manuel Belgrano”. No se podría sostener para el diario la figura "contaminante" de Guevara a nuestros "verdaderos" próceres puesto que la revolución cubana derivó en "en una tiranía implacable".

"El cuadro de Guevara en la galería de la Casa Rosada fue dispuesto por un gobierno que se aplicó a corroer con obstinación los vínculos fraternales entre los argentinos, las bases de la unión nacional que pregona la Constitución Nacional desde su primera página". $\underline{32}$

La impugnación de la figura del Che se articula con la cadena de sentido de la grieta. Es decir, el Che al igual que el kirchnerismo construirían poder a partir de incentivar el odio entre los ciudadanos y fomentar las divisiones sociales. Esa grieta fomentada desde el poder habría producido, según esta perspectiva, una cultura de trasgresión de las reglas. Otra de las tareas de la normalización era recuperar la autoridad estatal, pero no desde la perspectiva de autonomía política, sino del poder de sujetos acostumbrados al abuso de las normas.

"Demasiado lejos se ha llegado durante el kirchnerismo con el desconocimiento de los límites que toda protesta debe tener (...). Sin orden no hay convivencia posible; es volver a la ley de la selva. Una marcha o una concentración no puede ni debe dejar al resto de los ciudadanos sin paso para ir a trabajar, para concurrir a estudiar o para atender su salud". $\underline{33}$

Este debate se daba en medio de las primeras jornadas de protesta que surgían producto de las primeras medidas del gobierno de Macri. La concepción de regular la posibilidad de ejercer la protesta social se instala en la superficie redaccional del diario y señalan que "las interpretaciones ideológicas o políticas interesadas y extorsiones de lo más variadas han convertido ese ejercicio de derechos en un inmenso despropósito que urge resolver". $\underline{34}$

La Nación destacaba que la Argentina encara una nueva etapa en la que debería superar la gravosa herencia dejada por el kirchnerismo para luego consolidar el crecimiento y la estabilidad de su moneda. Para ello, los empresarios deben mirar las historias de los países exitosos como Alemania y Japón donde apoyaron el crecimiento y modernización principalmente en grupos empresarios locales. Lo importante es que ello "ocurrió en contextos competitivos, con bajas barreras arancelarias, sin proteccionismo y con un fuerte sentido emprendedor". $\underline{35}$

\section{Conclusiones}

Partimos de considerar al diario como la expresión comunicacional gráfica de los sectores liberal conservadores de la Argentina, pero que además de constituir un medio de información y formación de opinión, interviene en el espacio público en tanto sujeto con un núcleo de intereses propios, cuestión que le imprime una línea editorial definida y sostenida en el transcurso del tiempo.

El trabajo apuntó además a construir un conocimiento sobre los discursos de "derecha" en la Argentina contemporánea e indagar cómo se resignifica el pasado en los posicionamientos del presente y la forma en que 
construyen los relatos a partir de la reivindicación de distintos procesos históricos, tradiciones y figuras. Estas ideas y posicionamientos no han sido lo suficientemente indagados y resulta indispensable producir un conocimiento en esa área para dar cuenta del proceso abierto en 2015.

En la base argumental del discurso del diario, encontramos un conservadurismo económico construido semánticamente como liberalismo y la apelación a un discurso republicano, desde el cual se postula la defensa de la institucionalidad democrática para clausurar el proceso de democratización real de la vida social, política y económica. El concepto de República que aparece en La Nación, es el de un sistema político que clausura la democratización tanto política como económica y tiende a suplantar el conflicto de intereses inherente a la vida democrática tras una idea de orden social y normalización del país.

En la argumentación discursiva del medio, los avances políticos y sociales logrados durante los gobiernos populares, como así también la radicalización de las demandas de transformación del orden social, se presentan como desviaciones de la institucionalidad republicana, instituida por el orden conservador en el período de conformación del Estado-Nación.

Se puede concluir que desde diciembre de 2015 el punto nodal del discurso del medio será el de la "normalización de la vida republicana", como forma de construir simbólicamente un retroceso a lo actuado por los gobiernos denominados como populistas. El gobierno democrático debería asumirse como "el gobierno de todos", y ya no de una parte. En el desarrollo del trabajo se plasmó el significante central del medio que es el de la normalización y cómo ese significante va estructurando una cadena de equivalencias que va delineando una visión, un proyecto para la Argentina.

Las características de ese proyecto son retomar la senda de la lucha contra el populismo, el intervencionismo estatal, la protesta social, en el marco de un proyecto económico abierto al mundo. Dentro de esta perspectiva el gobierno de Macri representa esos intereses y abre nuevas posibilidades y afronta importantes desafíos. Creemos que esta aproximación al discurso del medio contribuye a la compresión de las estrategias de legitimación de la "avanzada conservadora” en nuestro país.

\section{Notas}

1 Héctor M. Guyot. "El día en que saltamos de un país a otro", en LA NACION, 12/10/2015.

$\underline{2}$ Este trabajo es parte de mi investigación sobre los discursos de la derecha en la Argentina contemporánea (CONICET) y del proyecto de incentivos Estudios en Historia Cultural de la Política y de la Violencia en Argentina. Siglos XIX-XXI, de la Facultad de Humanidades y Ciencias de la Educación, dirigido por el Dr. Guillermo Quinteros. Se agradecen profundamente los comentarios, la atenta lectura y las sugerencias a la Dra. Carolina Cerrano.

$\underline{3}$ El diario La Nación es uno de los periódicos de mayor importancia y tradición en la prensa gráfica argentina. La denominación de derecha o "liberal conservador" viene del propio medio. José Escribano manifestó que hacían un diario conservador-liberal (Ulanovsky, 1997). A su vez, podríamos retomar a Eccleshall (1984), quien distingue un conservadurismo libertario caracterizado por la conjunción de la valoración de lo tradicional y de las jerarquías preexistentes en una sociedad, con los ideales del libre mercado y la mínima injerencia del Estado. La intervención del Estado a través de políticas igualitarias es vista como el germen del totalitarismo, que subvierte el orden "natural" de la sociedad. Asimismo, ubicaremos al "liberal conservadurismo" como una expresión dentro de un paradigma mayor que es el pensamiento de "derecha".

4 La cuestión de la hegemonía desde la perspectiva de Laclau puede ampliarse en Howarth, (2008) y en Barros (2006). De la extensa obra de Laclau nos centramos en (Laclau, 1985a; 1985b; 1994; 1998; 2000; 2002 y 2005). 
$\underline{5}$ Como bien señala De Diego (2014) entender al periódico como productor de discursos sobre el campo político -y que, a su vez, interviene políticamente en las principales disputas- no es una perspectiva novedosa en los estudios de la prensa. Algunos enfoques clásicos como (Sidicaro, 1993; Saítta, 1998; Escudero, 1996). Otros se centraron en la relación de las empresas privadas de medios de comunicación, con el Estado y la democratización de las comunicaciones" (Marino, 2005: 45). Los trabajos de Martín Becerra y Guillermo Mastrini (Mastrini, 2005; Mastrini y Becerra, 2006; Becerra y Mastrini, 2009) son aportes muy relevantes en este sentido. Desde el análisis político de los medios en los últimos años existen importantes contribuciones (Dagatti, 2007; Califano, 2011; Kratje, 2008; González y Borrelli, 2009; Schaer, 2013; Montero y Vincent, 2013) Más que estudiar simples repercusiones del discurso político, son indagaciones que rastrean regularidades y particularidades de las construcciones de sentido de los periódicos, como agentes clave en las disputas públicas (De Diego, 2014).

6 $\mathrm{Si}$ bien es posible analizar los posicionamientos políticos de los periódicos en toda su superficie redaccional (portadas, crónicas, entrevistas, noticias en general y publicidades) focalizamos nuestro interés en las notas del género de opinión, entendiéndolas como el lugar donde emergen de manera explícita las dimensiones polémicas y argumentativas que orientan el perfil político de los diarios.

$\underline{7}$ En los últimos años, la prensa escrita ha sido objeto de numerosos análisis. En este campo de estudios se destacan los aportes de (Borrelli, 2012) quien revisó las principales posiciones editoriales del matutino Clarín frente al proyecto refundacional de la dictadura militar en la etapa 1976-1981. Para ello Borrelli (2012) analizó los posicionamientos del matutino sobre la experiencia dictatorial al cumplirse los aniversarios del golpe de Estado del 24 de marzo. Borrelli y Saborido (2011) amplían en el papel que desempeñó la prensa argentina en la dictadura, sujeta a una vigilancia estricta y a una legislación restrictiva de la libertad de expresión. Otros trabajos se centran en el período, iluminando cómo diversos medios nacionales y regionales construyeron sus lineamientos editoriales (Díaz, 2009). Otras investigaciones enfocaron en la dimensión argumentativa de los discursos autoritarios durante el siglo XX (Vitale, 2007 y 2009) y las conmemoraciones (Quinteros, 2013) y disputas simbólicas y políticas en distintas fechas "in-felices" (Jelin, 2002). En este sentido, nuestro abordaje se propone profundizar en nuestra actualidad reciente para dar cuenta de la forma de significar y construir lo que La Nación muestra como un cambio trascendental en el curso de la historia de nuestro país.

$\underline{8}$ Alejandro Katz. "Reconstruir una política de la buena fe", en $L A N A C I O N$, 10/12/2015.

9 Editorial. "Macri y el arte del acuerdo", en LA NACION, 11/12/2015.

10 Editorial. "Del antagonismo a la amistad social", en LA NACION, 11/12/2015.

11 Carlos María Galli. "Del antagonismo a la amistad social", en LA NACION, 11/12/2015.

12 Editorial. "Macri y el arte del acuerdo", en LA NACION, 11/12/2015.

13 Orlando J. Ferreres. "Una oportunidad para revertir la decadencia”, en LA NACION, 16/12/2015.

14 Gustavo Grobocopatel. "Con la potencia de una nación próspera”, en $L A N A C I O N, 16 / 12 / 2015$.

15 Alberto Benegas Lynch (h). "El fracaso de los acuerdos de precios y salarios", en LA NACION, 04/01/2016.

16 Ibídem.

17 Ibídem.

18 Editorial. "Estado pobre, militancia rentada", en $L A N A C I O N, 25 / 01 / 2016$.

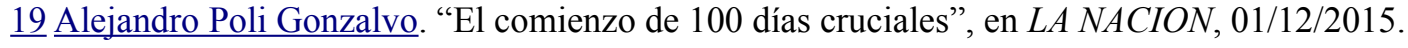

$\underline{20}$ Ibídem

$\underline{21}$ Joaquín Morales Solá. "Un gobierno sin derecho al error”, en LA NACION, 13/12/2015. 
$\underline{22}$ Jorge Fernández Díaz. "Algo doloroso está pasando en la calle”, en LA NACION, 20/12/2015.

23 Editorial. "Un gran salto cualitativo", en LA NACION, 03/01/2016.

24 Jorge Fernández Díaz. "La negociación en serio escandaliza a las almas bellas", en LA NACION, 10/01/2016.

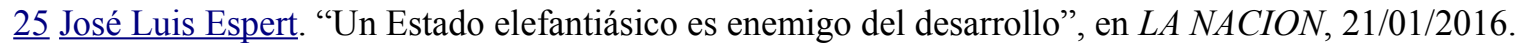

26 Ibídem.

$\underline{27}$ Ricardo Esteves. "Del modelo consumista al de inversión”, en LA NACION, 19/01/2016.

$\underline{28}$ Ibídem.

$\underline{29}$ Editorial. "En democracia no existe el delito de opinión”, en LA NACION, 06/01/2016.

$\underline{30}$ Editorial. "Los cuadros que se descuelgan”, en LA NACION, 07/01/2016.

$\underline{31}$ Ibídem.

$\underline{32}$ Ibídem.

$\underline{33}$ Editorial. "Las protestas y los derechos de todos", en $L A N A C I O N, 28 / 02 / 2016$.

$\underline{34}$ Ibídem.

$\underline{35}$ Editorial. "El perfil del empresario en la nueva etapa", en $L A N A C I O N, 22 / 03 / 2016$.

\section{Referencias Bibliográficas}

Baczko B. (1991). Los imaginarios sociales. Memorias y esperanzas colectivas, Ediciones Nueva Visión, Buenos Aires.

Basualdo E. (2001). Sistema político y modelo de acumulación en la Argentina. Quilmes, Universidad Nacional de Quilmes.

Barthes R. (1999). “El mito hoy”, en Mitologías, Buenos Aires, Siglo XXI Editores.O.

Bayer, y otros (2011) El Terrorismo de Estado en la Argentina: Apuntes sobre su historia y sus consecuencias, en Osvaldo Bayer; Atilio Boron; Julio Gambina; El otro en el discurso político argentino. Selección documental / Elvira Barillaro y Francisca La Greca - 1a ed. - Buenos Aires: Instituto Espacio para la Memoria.

Barros, S. (2006). "Inclusión radical y conflicto en la constitución del Pueblo populista", en Confines $\mathrm{N}^{\circ}$ 2-3, pp. 65-74.

Borrelli M. y Saborido J. (coord.) (2011). Voces y silencios. La prensa argentina y la dictadura militar (19761983), Eudeba, Buenos Aires.

Borrelli M. (2012). "Clarín frente a los años de Videla y Martínez de Hoz (1976-1981). Entre el apoyo político y la objeción económica”, en Cuadernos de H Ideas; La Plata; vol. 6 pp. 64 - 90.

Califano, B. (2011). "El discurso kirchnerista en los medios de comunicación: un análisis de caso". Ponencia presentada en las IX Jornadas de Sociología, Universidad Nacional de Buenos Aires.

Conno, D. (2012). "Hacia una democracia biopolítica”, en Rev. Sociedad \& Equidad, (4)

J. J. Courtine (1994), "Le tissu de la mémoire : quelques perspectives de travail historique dans les sciences du langage", en Langages, $\mathrm{N}^{\circ} 114$. 
Dagatti, M. (2007). "Una excursión por la bilis terrae. La asunción presidencial kirchnerista, según Clarín”, en Revista Argentina de Comunicación, Año 2, № 2, pp. 97-119.

De Diego J. (2014). “¿Discurso político o politicidad de los discursos? Una propuesta para pensar la relación entre kirchnerismo y prensa", en Kirchnerismo, mediatización e identidades políticas. Reflexiones en torno a la política, el periodismo y el discurso (2003-2008), Cuaderno de Trabajo del CIM-UNR.

De La Garza E. (2001). "La epistemología crítica y el concepto de configuración”, en Revista Mexicana de Sociología, No 1 , pp. 109-127

Diaz C. (dir.) (2009). Nos/otros y la violencia política. Buenos Aires Herald -. El Día - La Prensa / 1974-1982., La Plata, Al margen.

Eccleshall R. (1984). Ideologías políticas, TECNOS, Madrid.

Escudero, L. (1996). Malvinas: el gran relato. Fuentes y rumores en la información de guerra, Barcelona, Gedisa.

Fontcuberta, M. (1993). La noticia. Pistas para percibir el mundo, Barcelona, Paidós.

Foucault M. (2002). La arqueología del saber, Buenos Aires, Siglo XXI.

García Negroni M. (1988). "La destinación en el discurso político: una categoría múltiple”, en Lenguaje en Contexto I (1/2), Buenos Aires, pp. 85-111.

Howarth, D. (2008). "Hegemonía, subjetividad política y democracia radical", en Chrtichley S. y O. Marchart (Comps.). Laclau. Aproximaciones críticas a su obra, Buenos Aires, FCE.

González, M. y Borrelli M. (2009). "Entre víctimas y victimarios: el diario La Nación y la política de derechos humanos de Néstor Kirchner (2003-2007)”, en Question, vol 1, 23.

Jelin E. (2001). Los trabajos de la memoria, Siglo Veintiuno editores, España.

Jelin E., ed. (2002). Las conmemoraciones: Las disputas en las fechas "in-felices”, Madrid y Buenos Aires, Siglo XXI de España Editores y Siglo XXI de Argentina Editores.

Jelin E. (2005). "Los derechos Humanos entre el estado y la sociedad", en Dictadura y Democracia (1976-2001). Nueva Historia Argentina, Sudamericana, Buenos Aires.

Kratje, J. (2008). La orilla que se abisma. La construcción mediática del "conflicto por las papeleras". (Tesis de Licenciatura inédita). Facultad de Ciencias de la Educación Universidad Nacional de Entre Ríos.

Laclau, E. (1985a). "Tesis acerca de la Forma Hegemónica de la Política”, en Labastida, J. y Del Campo, M. (Comps.). Hegemonía y alternativas políticas en América Latina, México, Siglo XXI, pp. 19-44.

Laclau, E.(1985b). "Ruptura populista y discurso, anexo a Tesis acerca de la formación hegemónica de la política", en Labastida, J. y Del Campo, M. (Comps.). Hegemonía y alternativas políticas en América Latina, México, Siglo XXI.

Laclau, E. (1994). “Por qué los significantes vacíos son importantes para la política?”, en Emancipación y diferencia, Buenos Aires, Ariel.

Laclau, E. (1998). "Deconstrucción, pragmatismo y hegemonía", en Mouffe C. (Comp.) Deconstrucción y pragmatismo, Buenos Aires, Paidós.

Laclau, E. (2000). Nuevas reflexiones sobre la revolución de nuestro tiempo, Buenos Aires, Nueva Visión.

Laclau, E. (2002). "El análisis político del discurso: entre la teoría de la hegemonía y la retórica (entrevista)", en De Signis, (2). 
Laclau, E. (2005). La razón populista, Buenos Aires, Fondo de Cultura Económica.

Laclau, E. y Mouffe, C. (2004). Hegemonía y estrategia socialista. Hacia una radicalización de la democracia, Buenos Aires, Fondo de Cultura Económica.

Maingueneau, D (1984). “La polémica como interincomprensión”, en Genèses du discours, Bruselas, Mardaga.

Malamud A. y De Luca M. (coord.) (2011). La politica en tiempos de los Kirchner, Buenos Aires, EUDEBA.

Mc Gee Deutsch S. (2005). Las Derechas. La extrema derecha en la Argentina, el Brasil y Chile. 1890-1939, Buenos Aires, UNQ.

Pérez G. (2004). "Entre el poder del discurso y el discurso del poder: aproximaciones teóricas y metodológicas al estudio del discurso político", en Kornblit, Ana Lía (coord). Metodologías cualitativas en ciencias sociales, Buenos Aires, Biblos.

Montero, A. y Vicent, L. (2013). “Del ‘peronismo impuro' al 'kirchnerismo puro': la construcción de una nueva identidad política durante la Presidencia de Néstor Kirchner en Argentina (2003-2007)”, en revista Post data 18, $\mathrm{N}^{\mathrm{o}} 1$, Abril/2013, pp. 123-157.

Muñóz A. (2011). "Debates sobre la caracterización del giro a la izquierda en América Latina", en Todo aquel fulgor. La Política Argentina después del Neoliberalismo, Bs As, Nueva Trilce.

Novaro M. y Palermo V. (2003). Historia Argentina, La dictadura militar 1976/1983. Del golpe de estado a la restauración democrática, volumen 9 , Paidós.

Quinteros G. (Compilador) (2013). La conmemoración de la Revolución de Mayo. Prensa gráfica, historia y politica, siglos XIX-XXI, La Plata, EDULP

Rapoport M. (2000). “Historia económica, política y social de la Argentina”, Buenos Aires, Editorial Macchi.

Retamozo M. (2009). "Orden social, subjetividad y acción colectiva. Notas para el estudio de los movimientos sociales", en Athenea Digital: revista de pensamiento e investigación social, № 16, pp. 95-123.

Saborido, J. (2005). "El nacionalismo argentino en los años de plomo: la revista Cabildo y el proceso de reorganización nacional (1976-1983)", en Anuario de Estudios Americanos del Consejo Superior de Investigaciones Cientificas, Sevilla, volumen 62, No 1, pp. 235-270.

Saborido, J. y Borrelli (coords.) (2011). Voces y silencios. La prensa argentina y la dictadura militar (1976-1983), Bs. As., Eudeba.

Saítta S. (1998). Regueros de tinta. El diario Crítica en la década de 1920, Buenos Aires, Sudamericana.

Schaer, F. (2013). "De la campaña electoral a la asunción presidencial: la construcción del ethos previo de Néstor Kirchner en la prensa gráfica”. Ponencia presentada en el XI Congreso Nacional de Ciencia Política, (SAAPUNER). Paraná, Argentina.

Schuttenberg M., (2014). "La oposición al kirchnerismo. Una aproximación a los posicionamientos y reconfiguraciones de la centro derecha (2003-2011)”, en Revista Sudamérica, Mar del Plata, UNMP, vol. n³. pp. $5-74$

Schuttenberg, M. y Fontana J. (2013). “La Nación y la herencia perdida de la revolución, 2008-2011”, en Quinteros, Guillermo (Compilador). La conmemoración de la Revolución de Mayo. Prensa gráfica, historia y politica, siglos XIX-XXI, La Plata, EDULP.

Schuttenberg, M. y Fontana J. (2016). “Complicidad, acompañamiento y confrontación. Un análisis de los editoriales del diario La Nación publicados los 24 de marzo durante el período 1976-2014”, en Hallazgos. Revista de Investigaciones, Bogotá, vol. 13, pp. 233-260 
Sidicaro R. (1993). La política mirada desde arriba. Las ideas del diario La Nación 1909-1989, Buenos Aires, Sudamericana, pp. 425-426

Tocqueville, A. (1957). La democracia en América, México, FCE.

Ulanovsky, C. (1997). Paren las rotativas, Buenos Aires, Espasa Calpe.

Verón E. (1987). "La palabra adversativa", en El discurso político. Lenguajes y acontecimientos, Bs. As., Hachette.

Verón E. y Sigal S. (2004). Perón o muerte. Los fundamentos discursivos del fenómeno peronista, Eudeba, Buenos. Aires.

Vasilachis de Gialdino, I. (2009). "Los fundamentos ontológicos y epistemológicos de la investigación cualitativa", en Volumen 10, No. 2, Art. 30. Mayo.

Vitale A. (2007). "Prensa escrita y autoritarismo. El tópico de la caída hacia el abismo (1930- 1976)", en Revista de edición, lenguaje y cultura escrita $N^{\circ} 4$, pp. 47-62

Vitale A. (2009). "La dimensión argumentativa de las memorias discursivas. El caso de los discursos golpistas de la prensa escrita argentina (1930-1976)", en Forma y Función $N^{o} 1$, Volumen 22, Universidad Nacional de Colombia, pp. 125-144. 